Volume 8. No. 10, October 2020

International Journal of Emerging Trends in Engineering Research

Available Online at http://www.warse.org/IJETER/static/pdf/file/ijeter528102020.pdf

https://doi.org/10.30534/ijeter/2020/528102020

\title{
Numerical Analysis Of The Harmfulness Of The Fatigue-Corrosion Defect In A Metal Pipe Under Internal Pressure
}

\author{
Laidi ZAHIRI $^{1}$ *, Hamza KHATIB ${ }^{1}$, Mly Elhoussine ECH-CHHIBAT ${ }^{1}$, \\ Mustapha JAMMOUKH ${ }^{1}$, Zakaria MIGHOUAR ${ }^{1}$, Khalifa MANSOURI $^{\mathbf{1}}$ \\ ${ }^{1}$ SSDIA Laboratory, Hassan II University of Casablanca, ENSET of Mohammedia, Morocco, \\ *zahiri@enset-media.ac.ma
}

\begin{abstract}
The pipes used for the transport of fluids under pressure can show defects due to a manufacturing error or because of corrosion or an impact with a foreign body. These defects appear in the form of cracks, which propagate until the fracture of the mechanical structure. This paper deals with stress corrosion defects in the steel pipe API X52 and, in particular, fatigue corrosion defects. A proposed and validated numerical model is used to evaluate the harmfulness of this defect. This is achieved by acting on the variation in the frequency of stress application and on two corrosive environments. Based on the modified PARIS law, a parametric study is carried out, in which the main parameters that affect the corrosion fatigue life are highlighted. These parameters are the stress frequency, the stress intensity factor, and the rate of crack progression under the effect of stress corrosion. This study showed that the most harmful configuration is that of a corrosion defect with longitudinal internal crack at a low frequency of stresses in a corrosive environment.
\end{abstract}

Key words : Fatigue corrosion, Harmfulness, Numerical model, Semi-elliptical crack, Welded pipe.

\section{INTRODUCTION}

To ensure the continuity of the pressure service of pipes, the analysis of the resistance and the sizing calculation must consider in addition to the service loads, the impact of factors relating to the service environment [1]. The consequences of these factors may interfere with the effect of service loads and thus accelerate the deterioration of this equipment [2].

Corrosion of mechanical parts in service is a major design problem, the effect of corrosion being reflected on several levels [3]. The release of material from the surface of the corroded part (generalized or localized corrosion) generates geometric modifications and alterations of the surface condition [4]. The formation of localized corrosion results in zones with a high concentration of stress creating a privileged site for crack initiation and propagation. The presence of a corrosive environment near a crack can dramatically alter the mechanical properties of the material, in particular the parameters of resistance to crack propagation [5].

The purpose of this work is to evaluate numerically the harmfulness of crack defects when taking into account the surrounding environment, in particular the corrosive effect of the fluid being transported.

\section{PROBLEM AND CAUSES OF FAILURE}

Over the past 50 years, the demand for energy has continued to increase and production sites are often very far from consumption and operating centers. Hence, the need to transport fluid in pressurized pipes.
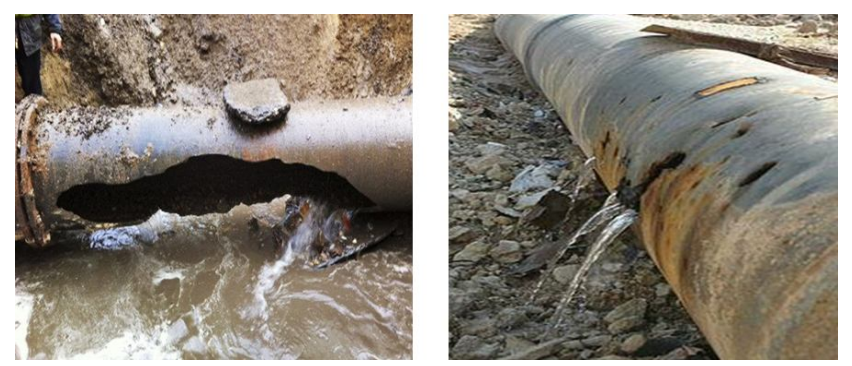

Figure 1: Problems to the transport of fluids under pressure [4]

These pipes can have defects due to a manufacturing error, an impact with a foreign body or cracks that propagate until the rupture of the structure. Figure 1 shows the break, leak, or explosion of a pipe. 


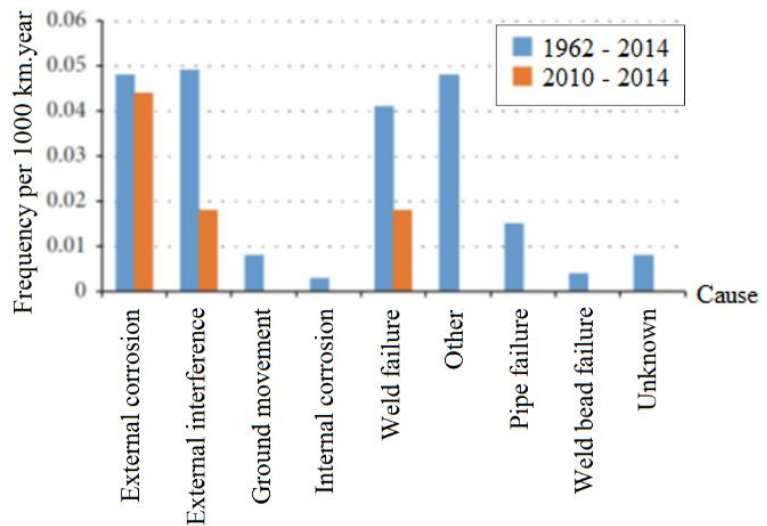

Figure 2: Causes of failure according to UKOPA [6]

According to UKOPA [6], from 2010 to 2014, the three main causes of failure, shown in Figure 2, are:

- External corrosion;

- External interference or indentations;

- Defects in welds.

\section{MODELING AND NUMERICAL ANALYSIS OF THE CRACK DEFECT IN A PRESSURIZED PIPE}

\subsection{Objectives of the numerical study}

The goal of this study is to numerically evaluate the stress intensity factor $\mathrm{K}_{\mathrm{I}}$ for semi-elliptical cracks of longitudinal and transverse orientations and different positions (external and internal) using the ANSYS calculation code [7]. This evaluation will allow us to estimate the number of cycles resulting to the rupture of the structure. The semi-elliptical crack parameters are shown in Figure 3.

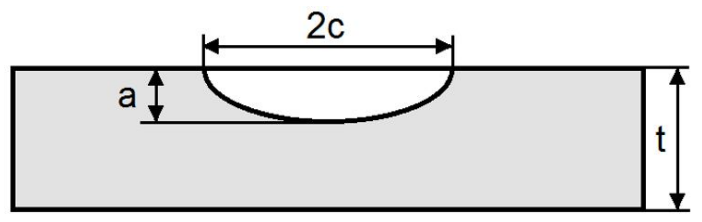

a: Depth of the crack c: Length of the crack t: Pipe thickness

Figure 3: Parameters of a semi-elliptical crack

\subsection{Evaluation of the number of cycles $\mathbf{N}$ at a failure}

To evaluate the number of cycles to fatigue $\mathrm{N}$. The model of PARIS [8], which introduces the closing effect of the crack, is used. PARIS's law is presented in (1) and uses as a parameter the effective stress intensity factor $\Delta \mathrm{K}_{\text {eff. }}$.

$\left(\frac{d a}{d N}\right)=C \cdot\left(\Delta K_{e f f}\right)^{m}$

(1)

This law (1) is applied to longitudinally welded pipes in the presence of crack defects, which are subject to a variable internal pressure, to determine the variation curve of $\mathrm{Ki}$ as a function of the crack depth a.
The numerical model developed and validated in the previous authors' study [9] is used to obtain the variance of the stress intensity factor as a function of crack depth $\left(K_{I}=f(a)\right)$ for the different cracks studied. This makes it possible to estimate the number of fatigue cycles using (2).

$$
N=\int_{N a}^{N_{f}} d N=\int_{a_{i n i}}^{a_{I C}} \frac{1}{C . \Delta K_{e f f}^{m}} d a
$$

\subsection{Geometry and Material}

The study is carried out on longitudinally welded tubes, the dimensions of which are shown in Figure 4. The material characteristics are shown in Table 1 and the constants of the Paris Law are shown in Table 2.

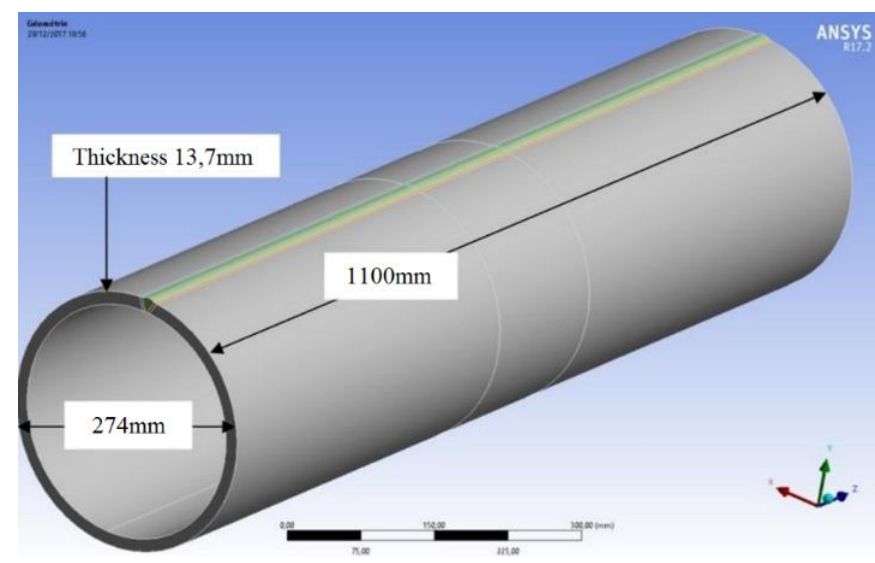

Figure 4: Pipe geometry

Table 1: Characteristics of the API X52 material [10]

\begin{tabular}{cccc}
\hline $\begin{array}{c}\text { Young } \\
\text { modulus }\end{array}$ & $\begin{array}{c}\text { Poisson's } \\
\text { ratio }\end{array}$ & $\begin{array}{c}\text { Yield } \\
\text { stress }\end{array}$ & $\begin{array}{c}\text { Critical stress } \\
\text { intensity factor }\end{array}$ \\
\hline$E(\mathrm{GPa})$ & $v$ & $\sigma_{e}(\mathrm{MPa})$ & $K_{I C}\left(\mathrm{MPa}^{0.5}\right)$ \\
\hline 201 & 0.3 & 403 & 121.18 \\
\hline
\end{tabular}

Table 2: Constants of the Paris Law [11]

\begin{tabular}{cc}
\hline $\mathbf{m}$ & $\mathbf{C}$ \\
\hline 2.74 & $3.3 \mathrm{E}^{-09}$ \\
\hline
\end{tabular}

\section{MODELING AND NUMERICAL ANALYSIS OF FATIGUE CORROSION DEFECT OF A TUBE UNDER PRESSURE}

\subsection{Stress corrosion}

Under static loading, and in the absence of the aggressive effect of the external environment, the mechanical resistance of a cracked part is conditioned by the stress intensity factor $\left(\mathrm{K}_{\mathrm{I}}\right)$ value which is observed at the $\operatorname{crack}\left(\mathrm{K}_{\mathrm{I}}<\mathrm{K}_{\mathrm{IC}}\right)$. 
As long as this condition is fulfilled, the state of the crack is stable. In the presence of the aggressive effect of an external environment, the state of the crack becomes unstable, and the preceding criterion $\left(\mathrm{K}_{\mathrm{I}}<\mathrm{K}_{\mathrm{IC}}\right)$ is no longer capable of ensuring resistance [12].

Stress Corrosion (SC) is the crack propagation mechanism observed during the static loading of a cracked part exposed to the effect of a corrosive environment. The state of the cracks under these loading conditions becomes unstable; it depends mainly on the loading applied, the material, and the nature of the corrosive fluid. Thus, a crack initially unable to propagate in an inert environment can bear under the combined effect of static stress and corrosion to cause the sudden rupture of the structure [13].

The stress corrosion process does not concern all materials; it is a mechanism that requires the meeting of certain conditions favoring initiation and propagation as shown in Figure 5. These conditions relate to the material, the environment, and loading [3].

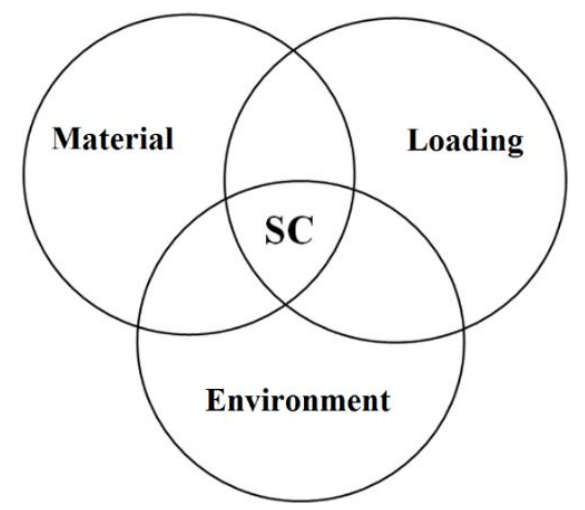

Figure 5: Factors needed to initiate stress corrosion

Stress corrosion occurs on sites where the level of stress is high, particularly cracks [1]. This revealed that the initiation of the stress corrosion process under the effect of static stress depends on the stress intensity factor $\mathrm{K}_{\mathrm{I}}$. The work of Brown [14] carried out on cracked specimens loaded in a corrosive environment, aimed to measure the needed time to observe the start of crack propagation as a function of the static intensity of the applied stress. The results showed that the time required to start the propagation is increased when the stress level is low.

If the applied stress intensity $\mathrm{K}_{\mathrm{I}}$ is below a limit value $\mathrm{K}_{\mathrm{I}, \mathrm{SC}}$, the crack will never progress. These results made it possible to identify the main parameter capable of assessing the mechanical resistance of a cracked part in a corrosive environment, and the limit stress intensity factor $\mathrm{K}_{\mathrm{I}, \mathrm{SC}}$. The first results show that the application of a lower static stress intensity $\mathrm{K}_{\mathrm{I}, \mathrm{SC}}$ does not affect the state of the crack. On the other hand, a static stress intensity higher than this limit value causes the crack to propagate [15]. The limit value of crack propagation $\left(\mathrm{K}_{\mathrm{I}, \mathrm{SC}}\right)$ remains a parameter intrinsically linked to the material and the environment. The kinetic of propagation by the effect of stress corrosion [16] is explained in Figure 6.

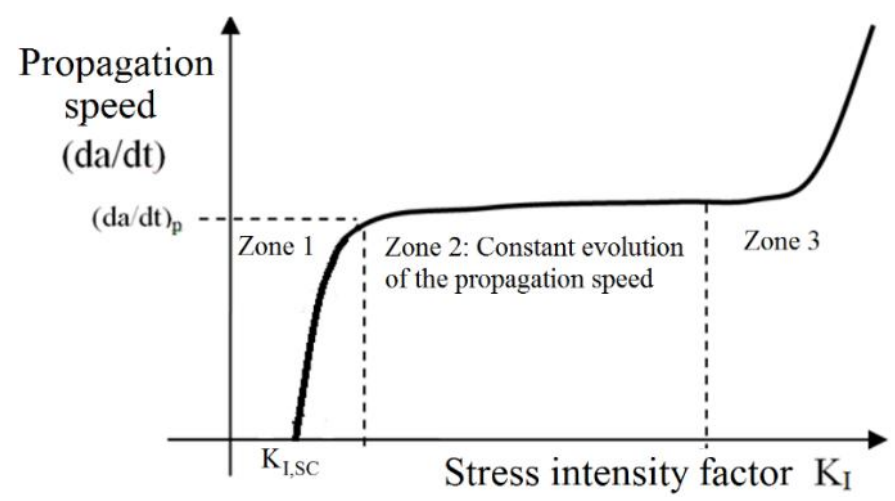

Figure 6 : Stress Corrosion Curve

It should be noted that the parameter that has the most effect on the propagation of a crack in a corrosive environment is the stress intensity factor $\left(\mathrm{K}_{\mathrm{I}}\right)$ calculated at the level of the crack. On this curve, there are three main zones:

Zone 1: In this zone, the material is weakly sensitive to the effect of stress corrosion. It is limited to weak values of loading. Therefore, the stress intensity is lower than $\mathrm{K}_{\mathrm{I}, \mathrm{SC}}$. The rate of progression of the crack $(\mathrm{da} / \mathrm{dt})$ is dependent on the stress intensity factor.

Zone 2: At this loading level, the stress corrosion process begins. Under the effect of the corrosion process mechanism and a stress intensity greater than $\mathrm{K}_{\mathrm{I}, \mathrm{SC}}$, the initial crack progresses with a constant speed called plate speed (da/dt)p. This speed remains stable despite the increase in the stress intensity factor caused by the propagation of this crack.

Zone 3: At this level, a similar behavior to that of zone 1 is found, where the speed $\mathrm{da} / \mathrm{dt}$ is influenced by the stress intensity factor $\mathrm{K}_{\mathrm{I}}$. The limit value of $\mathrm{K}_{\mathrm{I}}$ which gives rise to the start of zone 3 , is very significant. The increase in the propagation speed in this zone is generated by the effect of high values of $\mathrm{K}_{\mathrm{I}}$ which approach the value of $\mathrm{K}_{\mathrm{IC}}$.

Practically, the increase in the size of the crack produces an increase in the stress intensity, which produces an acceleration of the crack. Approaching the critical size, the speed reaches a significant level, thus resulting in the rupture of the structure.

The corrosive effect on a steel's cracking rate can be characterized by the stress corrosion curve. Two main parameters ensure a good identification of the stress corrosion curve, the limiting stress intensity $\left(\mathrm{K}_{\mathrm{I}, \mathrm{SC}}\right)$, which marks the start of the zone (I), and the plateau propagation speed (da/dt)p which identifies the rate when the $\mathrm{K}_{\mathrm{I}}$ factor becomes sufficiently greater than $\mathrm{K}_{\mathrm{I}, \mathrm{SC}}$ in the zone (II). 
Several experimental results show that the $\mathrm{K}_{\mathrm{I}, \mathrm{SC}}$ factor remains weakly influenced by the nature of the corrosive environment [16], on the other hand, this parameter strongly depends on the material. Thus, it is possible to associate the material with a characteristic value $\mathrm{K}_{\mathrm{I}, \mathrm{SC}}$ in the same way as the factor $\mathrm{K}_{\mathrm{IC}}$. The second parameter is the crack propagation speed $(\mathrm{da} / \mathrm{dt}) \mathrm{p}$ which depends on the material and the corrosive environment.

\subsection{Corrosion fatigue}

The study of the service life of the component under stress of cyclic loading indicates that this period can be divided into two main phases. The first phase is the most consistent, especially for steel pipes. During this phase, the stressed equipment ensures regular operation without the appearance of any external defect. At the end of this phase, the mechanical resistance deteriorates, which may contribute to the initiation of microcracks.

The second phase, which has a smaller extent, is governed by linear fracture mechanics mechanisms. The fracture mechanics tools provide models for estimating the crack propagation as a function of the applied stress intensity.

The analysis of the effect of corrosion on service life requires an analysis of the influence of corrosion on each of the two phases already listed. The experimental work carried out by Wadsworth and Hutching [17] show that the impact of corrosion is more significant on the crack propagation phase; this effect becomes more substantial by the appearance of the first micro-crack and the subsequent transition to the macro-crack.

\subsection{True corrosion fatigue}

In the presence of a crack, and under the effect of a cyclic stress intensity $\mathrm{K}_{\mathrm{I}}$ whose maximum value $\mathrm{K}_{\mathrm{IMAX}}$ is lower than $\mathrm{K}_{\mathrm{I}, \mathrm{SC}}$, the effect of stress corrosion on the propagation of the crack is insignificant (Figure 7).

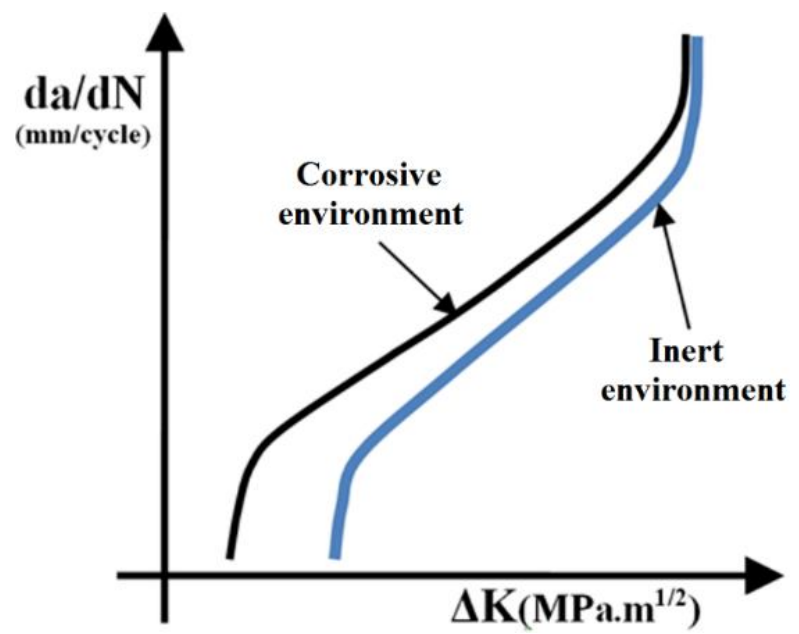

Figure 7: Effect of the true corrosion fatigue mechanism

The propagation of the crack, in this case, is due to the mechanical effect produced by each cycle of loading. The experimental work led by Brown et al. [14] shows that under these loading conditions, the action of the corrosive environment modifies the response of the material with respect to the resistance to crack propagation.

The curve links the crack propagation $(\mathrm{da} / \mathrm{dN})$ to the intensity of the applied stress is modified while keeping a linear behavior on a logarithmic scale. Thus, the PARIS law can be applied to estimate the duration of crack propagation by considering new parameters modified by the effect of corrosion. For materials that have a very high limit $\mathrm{K}_{\mathrm{I}, \mathrm{SC}}$ or in the case where the loading applied is weak compared to this limit, this mode of behavior in fatigue applies.

\subsection{Stress corrosion fatigue}

The stress corrosion mechanism will be initiated if the maximum value of the applied cyclic stress intensity exceeds the limit $\mathrm{K}_{\mathrm{I}, \mathrm{SC}}\left(\mathrm{K}_{\mathrm{MAX}}>\mathrm{K}_{\mathrm{I}, \mathrm{SC}}\right)$. Thus, the total propagation of the crack during a loading cycle is generated by the mechanical effect of the loading applied as well as the effect of the corrosive action. This corrosive action depends on the stress intensity level applied. The stress applied, therefore, governs the propagation of cracks by means of a mechanical effect and a process of stress corrosion [18].

Due to the nature of the stress corrosion process which requires a minimum threshold of initiation $\left(\mathrm{K}_{\mathrm{I}, \mathrm{SC}}\right)$, the curve of the propagation speed $(\mathrm{da} / \mathrm{dN}=\mathrm{f}(\Delta \mathrm{K}))$ will be influenced by corrosion after exceeding of the limiting level of the stress intensity. The $(\mathrm{da} / \mathrm{dN}=\mathrm{f}(\Delta \mathrm{K}))$ curve will be clearly influenced by the effect of corrosion if the value of $\mathrm{K}_{\mathrm{I}, \mathrm{SC}}$ is low and the speed (da/dt)p is significant, which is the case with high strength steels mechanical.

Under these conditions, the $(\mathrm{da} / \mathrm{dN}=\mathrm{f}(\Delta \mathrm{K}))$ curve will be markedly modified at low values of $\mathrm{K}_{\mathrm{MAX}}$ (Figure 8). The increase in the crack propagation speed will be more noticeable in this zone where the progression generated by the mechanical action still remains weak.

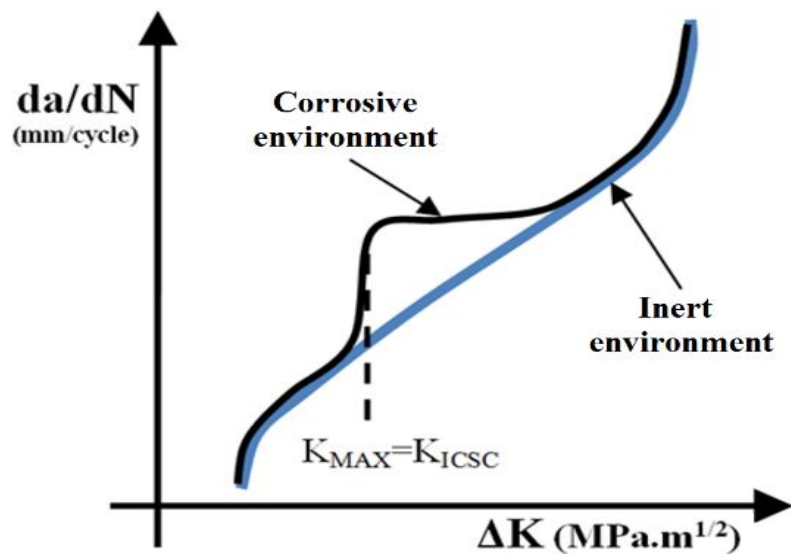

Figure 8: Effect of stress corrosion fatigue mechanism 
The effect of corrosion is less pronounced at high levels of the crack growth rate, and the total crack propagation speed converges towards the rate imposed by the mechanical effect. This convergence is clearly illustrated on the curve represented on logarithmic scales (Figure 8).

\subsection{Effect of stress frequency}

In the presence of a corrosive environment, and under the action of stress corrosion, crack propagation is governed by time and the intensity of the applied stress. The application of a high load that causes the starting condition $\left(\mathrm{K}_{\mathrm{I}}>\mathrm{K}_{\mathrm{I}, \mathrm{SC}}\right)$ induces crack progression with a speed $(\mathrm{da} / \mathrm{dt}) \mathrm{p}$. This value is deduced from the stress corrosion curve (SC). Knowing this speed of propagation of the crack during one second, one can deduce the speed of propagation for each cycle (3).

$$
\frac{d a}{d N}=\frac{1}{f} \frac{d a}{d t}
$$

From (3), it is noted that if the stress frequency is important, then the propagation of the crack after each cycle of loading is low.

\subsection{Prediction of corrosion fatigue life}

The estimation of corrosion fatigue life requires the mastery of the law of crack propagation, this law is concretized by the curve of evolution $(\mathrm{da} / \mathrm{dN}=\mathrm{f}(\Delta \mathrm{K}))$. The plot of the curve in the case of a corrosive environment is based on the one in an inert environment. This curve takes into account the two previous parameters as well as the stress frequency.

From experimental observations, Wei and Landes [19] proposed a model for calculating the crack propagation curve. This model uses the superposition between the crack propagation due to the mechanical effect and the propagation produced by the effect of stress corrosion as presented in (4).

$\left(\frac{d a}{d N}\right)_{F C}=\left(\frac{d a}{d N}\right)_{F}+\left(\frac{d a}{d N}\right)_{C}$

The term of propagation due to fatigue can be expressed using the PARIS law as in (5).

$$
\left(\frac{d a}{d N}\right)_{F}=C \cdot\left(\Delta K_{e f f}\right)^{m}
$$

The term of the crack propagation produced by the effect of stress corrosion is calculated by analyzing the cycle of evolution of the applied stress intensity, which will be considered sinusoidal.
During each load cycle, the stress corrosion process is initiated during a time interval when the applied stress intensity $\mathrm{K}_{\mathrm{I}}$ exceeds the initiation limit $\mathrm{K}_{\mathrm{I}, \mathrm{SC}}$. At this interval, the effect of corrosion accelerates the propagation of cracks.

By considering that the speed $(\mathrm{da} / \mathrm{dN})_{\mathrm{C}}$ is constant during the interval where $\left(\mathrm{K}_{\mathrm{I}}(\mathrm{t})>\mathrm{K}_{\mathrm{I}, \mathrm{SC}}\right)$, the expression of the speed of propagation due to the effect of corrosion can be written in a simplified form as in (6).

$$
\left(\frac{d a}{d N}\right)_{C}=\left(\frac{d a}{d t}\right)_{p} \times \frac{1}{f} \times \alpha
$$

$$
\begin{aligned}
\text { With } \alpha & =\frac{1}{2}-\frac{1}{\pi} \operatorname{Arcsin}\left(\frac{K_{I, S C}-K_{M O Y}}{K_{M A X}-K_{M O Y}}\right) \\
K_{M O Y} & =\frac{\left(K_{M A X}+K_{M I N}\right)}{2}
\end{aligned}
$$

$$
R c=\left(\frac{K_{I, S C}-K_{M O Y}}{K_{M A X}-K_{M O Y}}\right)
$$

By analyzing the variation of the coefficient $(\alpha)$, one can observe that it varies in the interval $[0,1]$. Figure 9 illustrates the evolution of the coefficient $(\alpha)$ depending on the ratio $(\mathrm{Rc})$. The parameter $\mathrm{Rc}$ is equal to zero when $\left(\mathrm{K}_{\mathrm{MAX}}=\mathrm{K}_{\mathrm{I}, \mathrm{SC}}\right)$ and it is maximum when $\left(\mathrm{K}_{\mathrm{MIN}}=\mathrm{K}_{\mathrm{I}, \mathrm{SC}}\right)$.

The effect of corrosion is more pronounced in the case of low value of Rc. Finally, the crack propagation speed produced by the effect of stress corrosion remains constant during the crack propagation cycles. On the other hand, the speed of propagation of the crack due to the mechanical effect of the cyclic load increases as a function of the stress intensity factor, which is a function of the size of the crack.

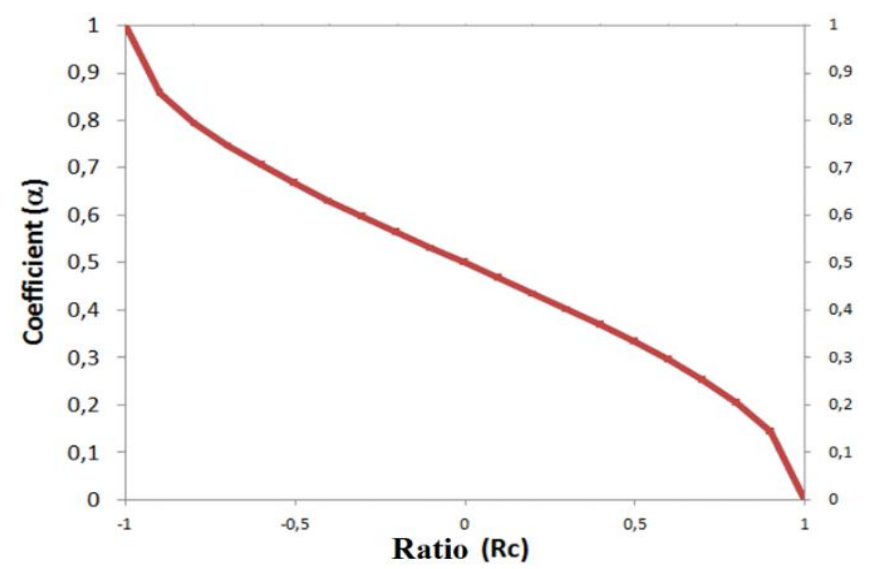

Figure 9: Evolution of the factor $(\alpha)$ depending on the ratio $(\mathrm{Rc})$ 
Laidi ZAHIRI et al., International Journal of Emerging Trends in Engineering Research, 8(10), October 2020, 6940 - 6949

After several cycles of loading, the stress intensity factor becomes more significant, thus the speed of propagation due to the applied loading increases and becomes more preponderant than the speed of propagation produced by the effect of stress corrosion, which remains stable. The sum of these two speeds thus becomes close to the speed produced by the cyclic loading, and the crack propagation curve approaches that initial one due to the mechanical effect in the vicinity of the strong values of $\mathrm{K}_{\mathrm{I}}$.

\section{PARAMETRIC STUDY}

\subsection{Effect of fatigue corrosion on the lifetime of an X52 steel pipe}

Pressure pipes are highly exposed to the risk of damage by corrosion fatigue. These structures can be subjected to cyclic loads caused by the variation of the pressure produced by stopping the flow of the fluid [20]. The exposition to prolonged cycles of loading worsens the structure defects.

To analyze the effect of corrosion on the harmfulness of cracks in pipes, the action of two fluids that have a corrosive effect on X52 steel pipes is studied in the present paper. The numerical model of the pipe is identical to the model used in a previous study led by authors [9-21]. This model is used in the current study with the aim of measuring the reduction in service life imposed by the action of each fluid. This would also make it possible to conduct a comparative analysis on the harmfulness of the two fluids and the parameters that accentuate this harmfulness.

The calculation of the corrosion fatigue life will be based mainly on the curve of the cracking law (da / $\mathrm{dN}=\mathrm{f}(\Delta \mathrm{K})$ ) obtained in a corrosive environment. This curve is calculated by considering the propagation curve in an inert medium (PARIS law) and the parameters of the stress corrosion curve.

\subsection{Parameters of the fatigue corrosion calculation model}

The steel X52 used mainly in pipes is prone to stress corrosion. The stress corrosion curve parameters are presented in Table 3 which provides information on corrosion in two different media. Several cases of cracks were studied in the previous study, in particular, those likely to exist in pipes welded longitudinally and located on the base material [9-21].

Table 3: Corrosion parameters of the two studied fluids

\begin{tabular}{cccc}
\hline \multicolumn{2}{c}{ Ethanol [22] } & \multicolumn{2}{c}{ Carbonate-Bicarbonate [23] } \\
\hline$K_{I, S C}$ & $(d a / d t) p$ & $K_{I, S C}$ & $(d a / d t) p$ \\
\hline $33 \mathrm{MPa} \cdot \mathrm{m}^{1 / 2}$ & $9.10^{-9} \mathrm{~m} / \mathrm{s}$ & $21 \mathrm{MPa} \cdot \mathrm{m}^{1 / 2}$ & $5.10^{-9} \mathrm{~m} / \mathrm{s}$ \\
\hline
\end{tabular}

The results of this study showed that the most harmful type of crack is the longitudinal crack located in the inner surface of the pipe. Hence, this type of crack is the one considered in the current study.

\section{RESULTS AND DISCUSSION}

\subsection{Effect of corrosion on crack propagation}

The crack propagation curve will be calculated by analyzing the effect of frequency as well as the effect of plate propagation speed which reflects the harmfulness of the fluid.

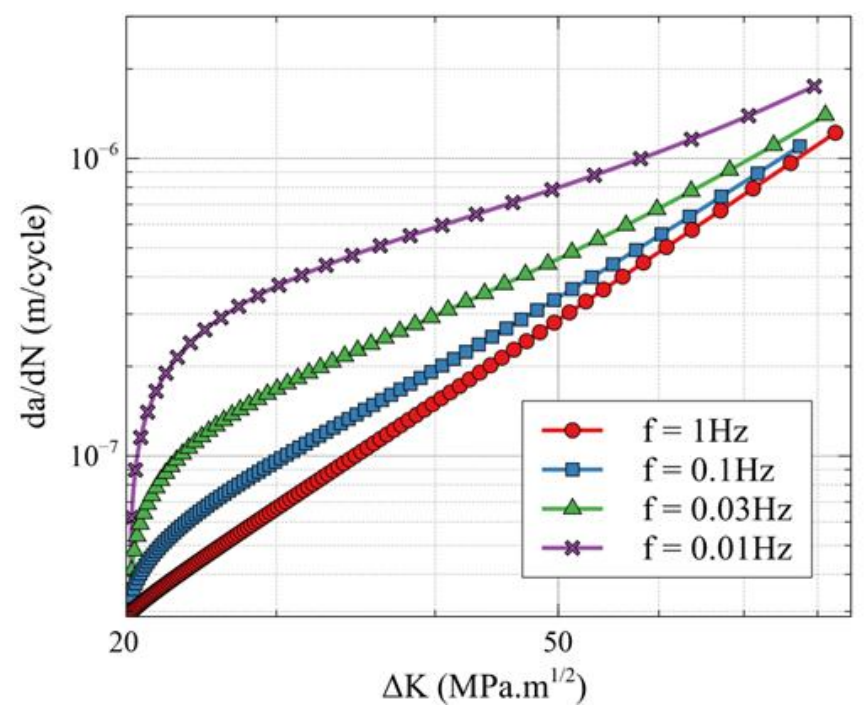

Figure 10: Crack propagation curve (Ethanol)

Figure 10 shows the effect of frequency on the crack propagation curve in the case of ethanol. For stress frequencies around $1 \mathrm{~Hz}$, the effect of corrosion is not significant. The time allowed for corrosion does not exceed 0.5 seconds, which generates a crack propagation of less than $4.5 \times 10-9 \mathrm{~m} /$ cycle. This can be considered as negligible compared to the speed produced by the mechanical effect of the order of $10-8 \mathrm{~m} /$ cycle.

It can be observed from the $0.1 \mathrm{~Hz}$ stress frequency curve that the corrosion effect is more noticeable. It is more prominent at the start of the crack propagation process, where the speed caused by the mechanical effect is less pronounced.

The increase in the size of the crack produces an increase in the stress intensity factor, which results in a high propagation speed due to the mechanical effect. The onset of the action of stress corrosion becomes visible and observable if the size of the initial crack is small enough to generate a stress intensity $\left(\mathrm{K}_{\mathrm{I}}\right)$ less than $\left(\mathrm{K}_{\mathrm{I}, \mathrm{SC}}\right)$, this stress intensity begins to progress under the effect of mechanical action until reaching the level of $\left(\mathrm{K}_{\mathrm{I}, \mathrm{SC}}\right)$ to produce the initiation of stress corrosion.

If the pipe is subjected to a corrosive environment and has a low value of $\mathrm{K}_{\mathrm{I}, \mathrm{SC}}$, the observation of the initiation of the propagation by corrosion is obtained at the level of small cracks. This exposes the pipe to a high risk of crack initiation even at the start of the operation. This micro-crack, which can 
cause a stress intensity factor lower than the threshold value $(\Delta \mathrm{Kth})$, is capable of propagating under the corrosion effect. This propagation can bring the stress intensity to a level which exceeds $(\Delta \mathrm{K}$ th $)$.

From Figure 11, we see the remarkable effect of a low value of the limit stress intensity factor $\left(\mathrm{K}_{\mathrm{I}, \mathrm{SC}}\right)$ observed at the curves of bicarbonates, this effect is materialized by the initiation of the stress corrosion mechanism from the first solicitation.

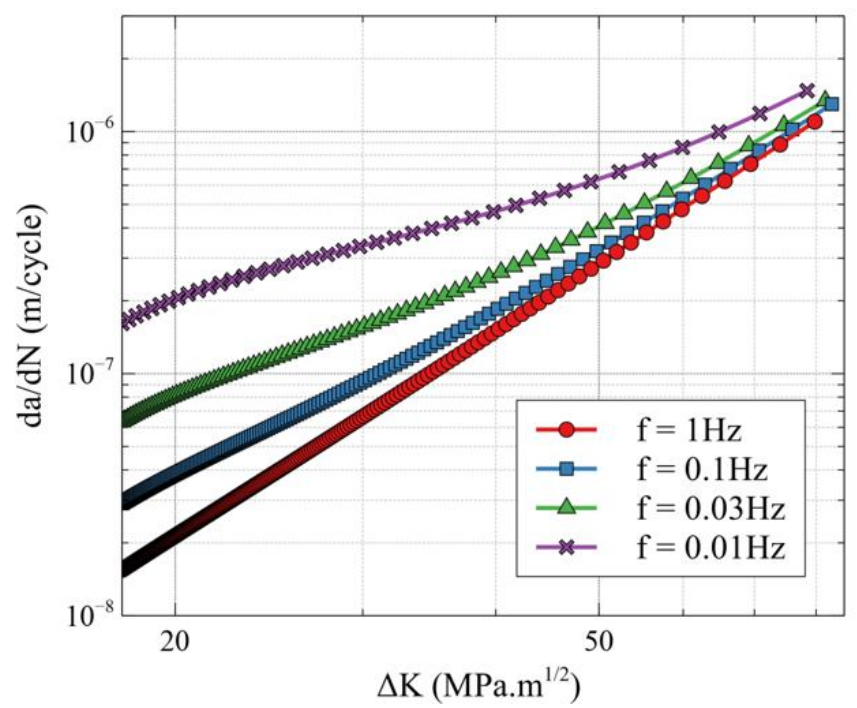

Figure 11: Crack propagation curve (Bicarbonate)

If the limit stress intensity factor $\left(\mathrm{K}_{\mathrm{I}, \mathrm{SC}}\right)$ is low, it is difficult to observe the beginning of the stress corrosion action. This finding makes this fluid more dangerous with respect to the stress intensity necessary to initiate the propagation of micro cracks, which frequently occur inside pipes following impact with foreign bodies or erosion.

From the reading of both curves (Figure 10 and Figure 11), it can be concluded that ethanol gives a greater margin of loading before the initiation of corrosion propagation. Therefore, it is less dangerous with respect to low values of stress intensity factor. However, the pipe filled with ethanol exhibits a stress corrosion process with more significant crack propagation rate than that of Bicarbonates.

The delay observed before the initiation of propagation at the level of the ethanol (Figure 10) will be taken up again after a certain number of cycles, and therefore life in the case of ethanol is found to be less significant. In order to prevent the initiation of crack propagation under the effect of stress corrosion, it is important to introduce the condition $\left(\mathrm{K}_{\mathrm{I}}<\right.$ $\mathrm{K}_{\mathrm{I}, \mathrm{SC}}$ ) as a resistance criterion. On the other hand, the parameter $\left(\mathrm{K}_{\mathrm{I}, \mathrm{SC}}\right)$ is not sufficient on its own to assess the effect of the harmfulness of corrosion defect.

\subsection{Effect of corrosion on the reduction of service life}

The analysis of the effect of the harmfulness produced by corrosion defect requires the introduction of the rate of propagation $(\mathrm{da} / \mathrm{dt}) \mathrm{p}$. This parameter can reduce or amplify the harmful effect depending on the corrosive environment.

In practice, the nature of the fluid to be transported is an imposed parameter, in the case where this fluid has a speed of progression (da /dt)p high, it will therefore be necessary to choose materials ensuring a limiting intensity $\left(\mathrm{K}_{\mathrm{I}, \mathrm{SC}}\right)$ which will delay the stress corrosion process and extend the maintenance intervals.

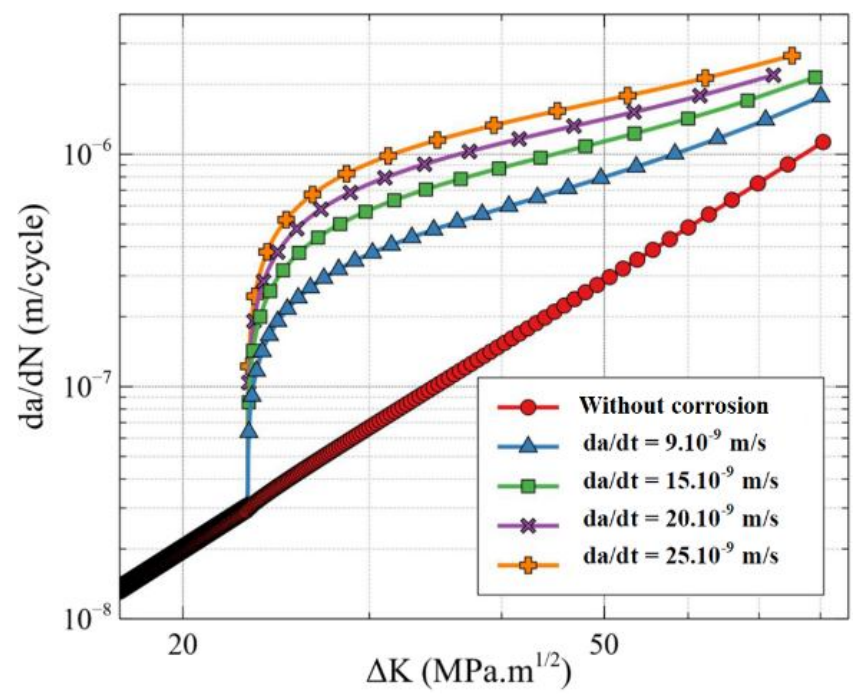

Figure 12: Effect of the parameter $(\mathrm{da} / \mathrm{dt}) \mathrm{p}$ on the crack propagation $\left(\mathrm{K}_{\mathrm{I}, \mathrm{SC}}=33 \mathrm{MPa} \cdot \mathrm{m}^{1 / 2}\right)$

Figures 12 and 13 show the effect of the two factors $\left(\mathrm{K}_{\mathrm{I}, \mathrm{SC}}\right)$ and (da/dt)p independently on the crack propagation curve for a frequency $\mathrm{f}=0.1 \mathrm{~Hz}$.

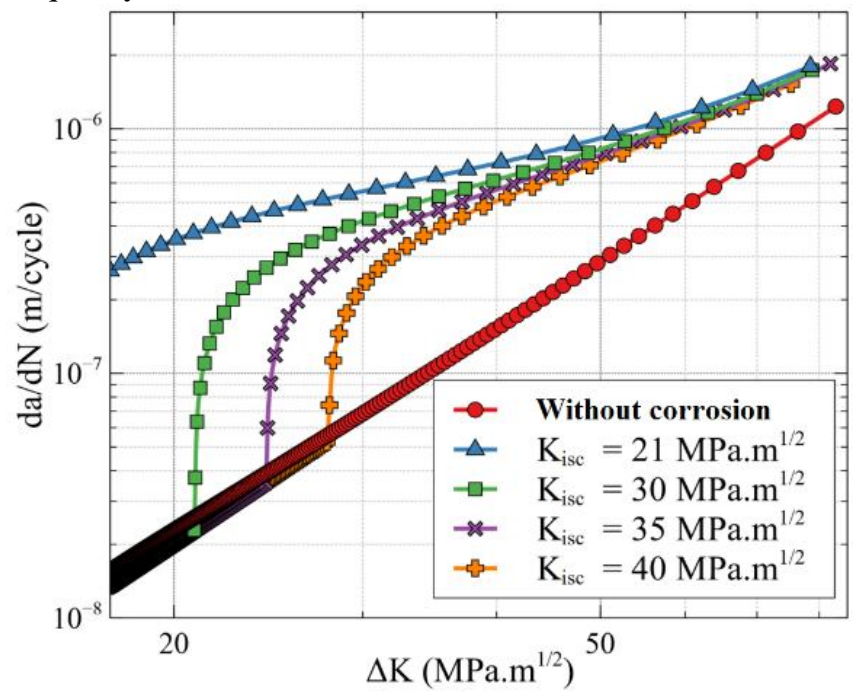

Figure 13: Effect of the parameter $\mathrm{K}_{\mathrm{I}, \mathrm{SC}}$ on the crack propagation $\left((\mathrm{da} / \mathrm{dt}) \mathrm{p}=9.10^{-9} \mathrm{~m} / \mathrm{s}\right)$

In the following section, we will present the combined effect of these two parameters, concentrating primarily on fatigue-corrosion life as a criterion for harmfulness. 
Laidi ZAHIRI et al., International Journal of Emerging Trends in Engineering Research, 8(10), October 2020, 6940 - 6949

\subsection{Effect of frequency on the reduction of fatigue life}

The stress frequency has a considerable effect on the crack propagation curve $(\mathrm{da} / \mathrm{dN}=\mathrm{f}(\Delta \mathrm{K}))$, this effect will be evaluated in terms of service life (Table 4). This table will allow us to choose the frequency to be adapted further in this study, in order to compare the effects of the two fluids.

The findings indicate that the effect of the frequency is very insignificant for high frequencies. The difference between the life of fatigue and the life of fatigue corrosion remains less than 5 per cent for a frequency of $1 \mathrm{~Hz}$. In this process, service life is governed by the effect of mechanical action.

The effect of corrosion on the service life becomes decisive from $\mathrm{f}=0.1 \mathrm{~Hz}$ where a reduction in the service life is observed which reaches $36 \%$. At a frequency $\mathrm{f}=0.01 \mathrm{~Hz}$, the drop in service life reaches critical levels, the number of cycles is reduced by more than half, which shows the very harmful effect of corrosion, particularly for structures subjected to heavy loads and for relatively long durations (pressure tanks, pressure pipes).

In the case of low loads, the decrease in service life due to the effect of stress corrosion is more noticeable. This is due to the nature of the stress corrosion mechanism, which has a stable propagation speed even for high load levels. Thus for high loadings, the propagation of the crack is mainly governed by the mechanical effect, and the effect of corrosion becomes more negligible.

Table 4: Effect of frequency on reduction of fatigue life $\left((\mathrm{da} / \mathrm{dt}) \mathrm{p}=9.10^{-9} \mathrm{~m} / \mathrm{s}\right)$

\begin{tabular}{|c|c|c|c|c|c|c|}
\hline $\begin{array}{c}\text { Frequency } \\
\text { f }(\mathbf{H z})\end{array}$ & $\begin{array}{c}\mathbf{P} \\
(\mathbf{M P a})\end{array}$ & $\mathrm{a} / \mathrm{c}$ & $\begin{array}{c}\mathbf{a}_{\mathbf{i c}} \\
(\mathbf{m m})\end{array}$ & $\begin{array}{c}\mathbf{N} \\
\text { (fatigue) }\end{array}$ & $\begin{array}{c}\mathbf{N} \\
\text { (fatigue / } \\
\text { corrosion) }\end{array}$ & $\begin{array}{c}\text { Differenc } \\
\text { e } \\
\%\end{array}$ \\
\hline \multirow{6}{*}{1} & \multirow{3}{*}{47.2} & 0,2 & 7.96 & 22888 & 22242 & $-3 \%$ \\
\hline & & 0,4 & 11.53 & 43617 & 42212 & $-3 \%$ \\
\hline & & 0,6 & 13.70 & 74605 & 71950 & $-4 \%$ \\
\hline & \multirow{3}{*}{59} & 0,2 & 6.65 & 11202 & 10990 & $-2 \%$ \\
\hline & & 0,4 & 9.17 & 21417 & 20927 & $-2 \%$ \\
\hline & & 0,6 & 12.06 & 37822 & 36774 & $-3 \%$ \\
\hline \multirow{6}{*}{0,1} & \multirow{3}{*}{47.2} & 0,2 & 7.96 & 22888 & 17877 & $-28 \%$ \\
\hline & & 0,4 & 11.53 & 43617 & 33079 & $-32 \%$ \\
\hline & & 0,6 & 13.70 & 74605 & 54997 & $-36 \%$ \\
\hline & \multirow{3}{*}{59} & 0,2 & 6.65 & 11202 & 9424 & $-19 \%$ \\
\hline & & 0,4 & 9.17 & 21417 & 17464 & $-23 \%$ \\
\hline & & 0,6 & 12.06 & 37822 & 29704 & $-27 \%$ \\
\hline \multirow{5}{*}{0,05} & \multirow{3}{*}{47.2} & 0,2 & 7.96 & 22888 & 14821 & $-35 \%$ \\
\hline & & 0,4 & 11.53 & 43617 & 27003 & $-38 \%$ \\
\hline & & 0,6 & 13.70 & 74605 & 44048 & $-41 \%$ \\
\hline & & 0,2 & 6.65 & 11202 & 8178 & $-27 \%$ \\
\hline & 59 & 0,4 & 9.17 & 21417 & 14873 & $-31 \%$ \\
\hline
\end{tabular}

\begin{tabular}{ccccccc} 
& & 0,6 & 12.06 & 37822 & 24745 & $-35 \%$ \\
\hline \multirow{4}{*}{0,01} & & 0,2 & 7.96 & 22888 & 6623 & $-71 \%$ \\
& 47.2 & 0,4 & 11.53 & 43617 & 11689 & $-73 \%$ \\
\cline { 2 - 6 } & & 0,6 & 13.70 & 74605 & 17914 & $-76 \%$ \\
\hline \hline
\end{tabular}

6.4. Analysis of the reduction in service life produced by fluids

From Table 5, the frequencies of $0.1 \mathrm{~Hz}$ and $0.05 \mathrm{~Hz}$ are chosen to compare the effect of the two fluids, given that the reduction in service life obtained remains an average reduction compared to the reductions obtained for the other frequencies.

It can be seen that despite the fact that ethanol has a higher limit stress intensity $\left(\mathrm{K}_{\mathrm{I}, \mathrm{SC}}\right)$, the reduction in the service life that is generated remains more remarkable than that produced by bicarbonate. This shows that if the corrosion process under stress is initiated, the criterion of harmfulness no longer becomes $\left(\mathrm{K}_{\mathrm{I}, \mathrm{SC}}\right)$ but that of the speed of propagation (da/dt)p.

Thus, considering two identical cracked pipes, one transporting ethanol and one transporting bicarbonate. It is noted that the mechanical effect will produce the progression of this crack on the two pipes with the same kinetics. If the size of the crack reaches a sufficient size, the effect of corrosion will begin to appear in the pipe carrying the bicarbonate.

This may trigger the process of stress corrosion.

Table 5: Reduced service life induced by the interaction with the studied fluids

\begin{tabular}{|c|c|c|c|c|c|c|c|}
\hline $\begin{array}{c}\text { Flui } \\
\text { d }\end{array}$ & $\begin{array}{c}\text { Frequenc } \\
\mathbf{y} \\
\mathbf{f}(\mathbf{H z})\end{array}$ & $\begin{array}{c}\mathbf{P} \\
(\mathbf{M P a} \\
)\end{array}$ & $\mathrm{a} / \mathrm{c}$ & $\begin{array}{c}\mathbf{a}_{\mathrm{ic}} \\
(\mathbf{m m})\end{array}$ & $\begin{array}{c}\mathrm{N} \\
\text { (fatigue } \\
\text { ) }\end{array}$ & $\begin{array}{c}\mathbf{N} \\
\text { (fatigue / } \\
\text { corrosion) }\end{array}$ & $\begin{array}{c}\text { Differenc } \\
\text { e } \\
\%\end{array}$ \\
\hline \multirow{12}{*}{ 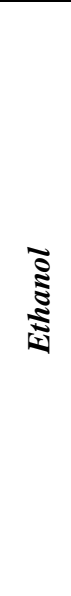 } & \multirow{6}{*}{0,1} & \multirow{3}{*}{47.2} & 0,2 & 7,96 & 22888 & 17877 & $-28 \%$ \\
\hline & & & 0,4 & 11,53 & 43617 & 33079 & $-32 \%$ \\
\hline & & & 0,6 & 13,70 & 74605 & 54997 & $-36 \%$ \\
\hline & & \multirow{3}{*}{59} & 0,2 & 6,65 & 11202 & 9424 & $-19 \%$ \\
\hline & & & 0,4 & 9,17 & 21417 & 17464 & $-23 \%$ \\
\hline & & & 0,6 & 12,06 & 37822 & 29704 & $-27 \%$ \\
\hline & \multirow{6}{*}{0,05} & \multirow{3}{*}{47.2} & 0,2 & 7,96 & 22888 & 14821 & $-54 \%$ \\
\hline & & & 0,4 & 11,53 & 43617 & 27003 & $-62 \%$ \\
\hline & & & 0,6 & 13,70 & 74605 & 44048 & $-69 \%$ \\
\hline & & \multirow{3}{*}{59} & 0,2 & 6,65 & 11202 & 8178 & $-37 \%$ \\
\hline & & & 0,4 & 9,17 & 21417 & 14873 & $-44 \%$ \\
\hline & & & 0,6 & 12,06 & 37822 & 24745 & $-53 \%$ \\
\hline 0 & 0,1 & & 0,2 & 7,96 & 22888 & 18842 & $-18 \%$ \\
\hline
\end{tabular}


Laidi ZAHIRI et al., International Journal of Emerging Trends in Engineering Research, 8(10), October 2020, 6940 - 6949

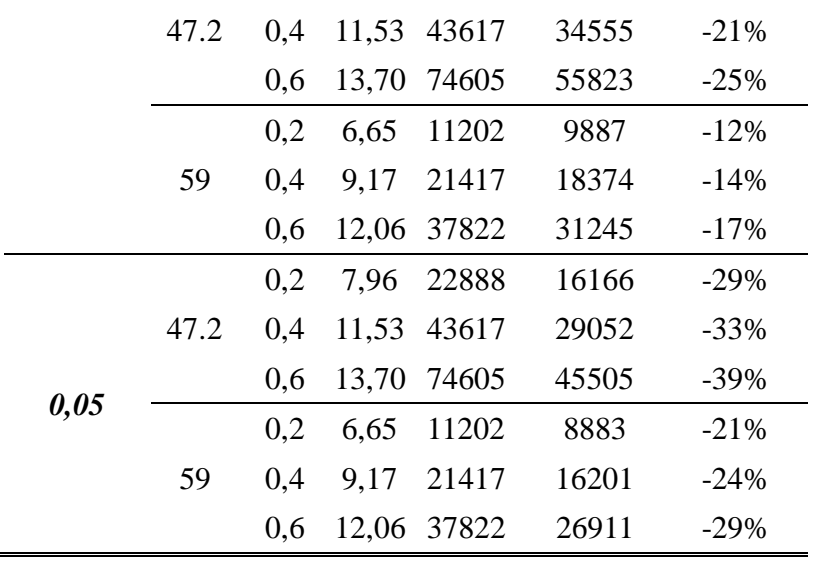

In the case of pipe transporting ethanol, the progression of the size of the crack under the mechanical effect must continue to reach a size that induces a stress intensity $\left(\mathrm{K}_{\mathrm{I}}=33 \mathrm{MPa} \cdot \mathrm{m}^{1 / 2}\right)$. The propagation of the crack in the case of ethanol will occur at a faster rate which will allow it to exceed, after a certain number of cycles, the size of the crack in the case of bicarbonate. These findings clearly show that in the case of an accidental defect (impact, erosion...), the interval of intervention to repair the defected pipe before the rupture of the structure is very limited.

\section{CONCLUSION AND PERSPECTIVES}

The analysis of the effect of corrosion on the fatigue cracking process under cyclic loading, allowed us to develop the necessary steps to numerically quantify the effect of corrosion on the service life of a steel pipe. This work allowed to estimate the new crack propagation curves $(\mathrm{da} / \mathrm{dN}=\mathrm{f}(\Delta \mathrm{K}))$ which take into account the influence of two corrosive environments and estimates the drops in service life caused by corrosion. This analysis revealed a set of main parameters that affect corrosion fatigue life. In addition to the parameters relating to loading and geometry, an additional set of parameters have been highlighted due to their strong influence on the deterioration of the fatigue-corrosion life.

The first parameter is the stress frequency, which makes it possible to take into account the loading period. It should be noted that this parameter is practically dependent on the service environment of the equipment being examined. Pipes and pressure equipment are systems undergoing low-frequency stress loading. This aggravates the effect of corrosion on crack propagation.

The second parameter is the limiting stress intensity $\left(\mathrm{K}_{\mathrm{I}, \mathrm{SC}}\right)$ which reflects the sensitivity of the material to the stress corrosion process. A high value of the factor $\left(\mathrm{K}_{\mathrm{I}, \mathrm{SC}}\right)$ delays the initiation of the effect of corrosion on the crack propagation. The third parameter is the plate speed $(\mathrm{da} / \mathrm{dt})_{\mathrm{p}}$ which reflects the kinetics of crack progression under the effect of stress corrosion. The obtained results show the frequency domains which present an aggressive effect. For loading cycles of 100 seconds, the drop in service life exceeds $70 \%$ of the initial fatigue life. The combination of the effect of the two parameters $\left(\mathrm{K}_{\mathrm{I}, \mathrm{SC}}\right)$ and $(\mathrm{da} / \mathrm{dt})_{\mathrm{p}}$ showed that each one presents an influence which cannot be neglected.

As a result, a sufficient value of $\left(\mathrm{K}_{\mathrm{I}, \mathrm{SC}}\right)$ does not necessarily guarantee a longer life period of a cracked pipe, it is therefore necessary to incorporate the effect of speed $(\mathrm{da} / \mathrm{dt})_{\mathrm{p}}$ in order to correctly estimate fatigue life. This finding makes it possible to make a practical plan for the choice of material according to the transported fluid. This can be achieved by taking into account the two phases; crack initiation (choice of high $\mathrm{K}_{\mathrm{I}, \mathrm{SC}}$ ) and crack propagation (choice of low speed $(\mathrm{da} / \mathrm{dt})_{\mathrm{p}}$ ). This could reduce the effect of corrosion on crack propagation.

In accidental cases and if the crack is initiated by an external effect, the low rate of propagation will reduce the time required for the crack to reach its critical size. This is highly appreciated because it enables to extend the inspection and maintenance intervals for pipes carrying corrosive fluids.

\section{REFERENCES}

1. G. S. Chen, C. M. Liao, K. C. Wan, M. Gao and R. P. Wei. Pitting corrosion and fatigue crack nucleation, ASTM, pp. 18-33, 1997.

2. H. J. Russell. Stress-Corrosion Cracking Materials Performance and Evaluation, ASM int, pp. 339, 1993.

3. Y. Frank Cheng. Stress corrosion cracking of pipelines, Wiley, pp. 8, 2013.

4. F. Caleyo, A. Valor, J. C. Velázquez and J. M. Hallen. On the Estimation of the Probability of Failure of Single Corrosion Defects in Oil and Gas Pipeline, in NACE Corrosion Risk Management Conf, Houston TX, 2016.

5. T. W. Crooker and E. A. Lange. Corrosion fatigue crack propagation for some new high strength structural steels, Journal of Basic Eng, pp. 570-574, 1969.

6. UKOPA, pipeline product loss incidents and faults report (1962-2014), (2015).

7. H. H. Lee. Finite Element Simulation with ANSYS Workbench 17, SDC Publications, 2017.

8. P. C. Paris and F. A. Erdogan. Critical Analysis of Crack Propagation Laws, J. of Basic Eng, Vol. 85(4), pp. 528-533, 1963.

9. L. Zahiri, Z. Mighouar, H. Khatib, K. Mansouri and B. Salhi. Fatigue Behavior Of Longitudinal Welded Pipes Subjected To Cyclic Internal Pressure, Containing Welding Defects, Int. J. of Mechanical Engineering \& Technology, Vol. 9(3), pp. 560-569, 2018.

10. B. Vargas-Arista, A. Albiter, F. García-Vázquez, O. M. Camargo, and J. M. Hallen. Effect of natural aging on the microstructural regions, mechanical properties, 
corrosion resistance and fracture in welded joints X52 steel pipeline, Rev. Metal. Vol. 50(3), 2014.

11. M. Dadfarnia and P. Sofronis. Project Report (SoCalGas), Department of Mechanical Science and Eng., University of Illinois at Urbana-Champaign, 2016.

12. G. Bourse, Contribution to the study of fatigue and corrosion cracking rates in E36 steel, Thesis, Université des ST, Lille, pp. 13-22, 1979.

13. J. C. Newman, Fracture Analysis of Surface and Through-Cracked Sheets and Plates, Engineering Fracture Mechanics, Vol. 5(3), pp. 667-689, 1973.

14. B. F. Brown and C. D. Beachem. A study of the stress factor in corrosion cracking by use of the pre-cracked cantilever beam specimen, corrosion science, $\mathrm{pp}$. 745-748, 1965.

15. T. Magnin. Mechanisms of corrosion-fatigue of metallic alloys, Rev. Met. P., Vol. 99, pp. 423-432, 2002.

16. V. S. Raja and T. Shoji. Stress corrosion Cracking Theory and practice, WOODHEAD, pp. 3-6, 2011.

17. R. P. Wei, S. R. Novak and D. P. Williams. Some important considerations in the development of stress corrosion cracking test methods, Fritz Engineering Laboratory Report, pp. 1-8, 1971.

18. E. U. Lee. Review of corrosion fatigue, Naval air development center, Pennsylvania, pp. 5, 1981.

19. R.P. Wei and J. D. Landes. Correlation between sustained load and fatigue crack growth in high strength steels, Mat. Res. and Standards, p. 25, 1969.

20. Z. Mighouar, L. Zahiri, H. Khatib and K. Mansouri. Damage Accumulation Model for Cracked Pipes Subjected to Water Hammer, Advances in Sci., Tech. and Eng. Systems Journal, Vol. 5(4), pp. 523-530, 2020.

21. L. Zahiri, Z. Mighouar, K. Mansouri and Mly El Ech-chhibat. Modeling and numerical analysis of the harmfulness of the fatigue-corrosion defect in a pressure tube, in 1st Int. Conf. on Research in Applied Mathematics and Computer Science ICRAMCS, 2019.

22. J. W. Sowards, T. S. Weeks and J. D. McColskey. The influence of simulated fuel-grade ethanol on fatigue crack propagation in pipeline and storage-tank steels, Corrosion Science, pp. 413- 425, 2013.

23. F. M. Song. Predicting the mechanisms and crack growth rates of pipelines undergoing stress corrosion cracking at high pH, Corrosion Science, Vol. 51, pp 2657-2674, 2009. 